\title{
A strategic energy technology policy towards 2050: no-regret strategies for European technology push
}

\section{Sophia Ruester*}

Florence School of Regulation,

European University Institute,

Via Boccaccio 151, 50133 Firenze, Italy

E-mail: sophia.ruester@eui.eu

*Corresponding author

\section{Sebastian Schwenen}

German Institute for Economic Research,

DIW Berlin, Mohrenstraße 58,

10117, Berlin, Germany

E-mail: sschwenen@diw.de

\section{Matthias Finger}

École Polytechnique Fédérale de Lausanne,

Station 5 (ODY 3.03), 1015 Lausanne, Switzerland

E-mail: matthias.finger@epfl.ch

\section{Jean-Michel Glachant}

Loyola de Palacio Chair,

European University Institute,

Via Boccaccio 151, 50133 Firenze, Italy

E-mail: jean-michel.glachant@eui.eu

\begin{abstract}
As current policy frameworks are expiring soon, the EU is revisiting its energy technology policy for the post-2020 horizon. The main long-run objective for energy technology policy is to foster the achievement of ambitious EU goals for decarbonisation. We discuss how European energy technology policy towards 2050 can be effective despite: 1) uncertain carbon prices; 2) uncertain technological change; and 3) uncertain or alternating policy paradigms shifting the focus from decarbonisation towards competitiveness or energy supply security. Public support to innovation in energy technologies is needed to correct for market failures and imperfections, as well as to fully exploit trade opportunities of such technologies on global markets. Benefits from EU intervention can be expected from the coordination of national policies. Effective European technology push should put strong emphasis on pushing consumption-oriented and enabling technologies, as these offer a no-regret strategy vis-à-vis any future context.
\end{abstract}

Keywords: European energy technology policy; decarbonisation; innovation; uncertain policy context; technology push. 
Reference to this paper should be made as follows: Ruester, S., Schwenen, S., Finger, M. and Glachant, J-M. (2013) 'A strategic energy technology policy towards 2050: no-regret strategies for European technology push', Int. J. Energy Technology and Policy, Vol. 9, No. 2, pp.160-174.

Biographical notes: Sophia Ruester is a Researcher at the Florence School of Regulation (European University Institute, Florence, Italy). She receives her $\mathrm{PhD}$ in Economics (2010) and her Diploma in Industrial Engineering (2006), both from the Technical University of Dresden, Germany. She has published articles on various issues related to European energy policy and corporate strategies in (liquefied) natural gas markets in different academic journals, including the Journal of Institutional Economics, Utilities Policies, Energy Policy, and Energy. She is also the Managing Editor of Economics of Energy \& Environmental Policy.

Sebastian Schwenen is a Researcher at the German Institute for Economic Research (DIW) in Berlin. He holds a PhD in Economics (2011, Copenhagen Business School) and a Diploma in Economics (2007, Humboldt University of Berlin). His research interests are in the areas of energy economics and industrial organisation, with most of his recent work focusing on the economics of supply security in electricity markets. He also spent one academic year as a visiting $\mathrm{PhD}$ student at the London School of Economics and worked as a Post-Doctoral Researcher at the Robert Schuman Centre for Advanced Studies at the European University Institute.

Matthias Finger is a Professor at the Ecole Polytechnique Fédérale de Lausanne, where since 2002 he directs the Chair Management of Network Industries, as well as a part-time Professor at the Florence School of Regulation. After having been an Assistant Professor at Syracuse University, New York (1989-1991) and Associate Professor at Columbia University, New York (1992-1994), he was appointed Full Professor at the Swiss Graduate School of Public Administration in Lausanne in 1995. There, he developed his research on the transformation of network industries in the postal, telecommunications, railways, electricity, air transport, and water sectors. He also edits the journal Competition and Regulation in Network Industries.

Jean-Michel Glachant is the Director of the Loyola de Palacio Chair and of the Florence School of Regulation. He has been an Advisor of DG ENER, DG COMP and DG RESEARCH at the European Commission and of the French Energy Regulatory Commission. He is or has been a coordinator or Scientific Advisor of several European research projects (e.g., SESSA, CESSA, Reliance, EU-DEEP, RefGov, THINK). He is a research partner in the CEEPR at MIT, the EPRG at Cambridge University, the EEI at the University of Leuven and the GIS Larsen at the University Paris Sud. He is also the Editor-in-Chief of Economics of Energy \& Environmental Policy.

\section{Motivation}

In 2009, the European Council agreed on the long-term EU climate policy goal to reduce greenhouse gas emissions inside the EU to at least 80\% below 1990 levels by 2050 . Achieving this goal poses significant challenges for EU policy makers. Most low-carbon energy technologies are not yet competitive or even not technologically proven. Moreover, the current period of austerity has imposed tight constraints on national 
budgets and has forced governments to rethink fiscal policies, including support for research and innovation. Different Member States have recently abandoned several expensive energy policies, mostly those promoting clean energy technologies. Current policy frameworks on the European level are running out, such as the Strategic Energy Technology Plan (SET Plan) and the EU has to establish a lasting policy framework that fosters the achievement of its ambitious commitments for decarbonisation by 2050 .

In the light of these recent developments, this article discusses how European energy technology policy towards 2050 can be effective despite:

1 uncertain carbon prices

2 uncertain technological change

3 uncertain or alternating policy paradigms shifting the focus from decarbonisation towards competitiveness or energy supply security.

We first argue that public support to innovation in low-carbon technologies is needed to correct for market failures and imperfections, as well as to fully exploit trade opportunities of such technologies on global markets. Benefits from EU intervention can be expected from the coordination of national policies, and European co-funding also can leverage additional national and private funds. We finally argue that European technology push - to offer a feasible no-regret strategy vis-à-vis uncertain energy market and political developments on the way to 2050 - should strongly emphasise pushing consumption-oriented and enabling technologies.

This article is organised as follows. Section 2 derives the origins of and the justification for technology push and illustrates benefits from EU involvement and European co-funding of innovation. Section 3 introduces the three major sources of uncertainties that policymakers have to take account of when designing a future energy technology policy. Having these uncertainties in mind, Section 4 derives a robust and feasible policy, with respect to its design and technology-specific content. Section 5 concludes.

\section{Rationales for European technology push}

Policy intervention needs to be justified in terms of its economic or social benefits. To this end, this section establishes rationales for public support to low-carbon innovation as well as for EU involvement in this respect. Finally, this section briefly discusses the effectiveness of currently implemented European technology push.

\subsection{Rationales for technology push}

As discussed in-depth in Ruester et al. (2013), policy intervention in research, development, demonstration and deployment (RDD\&D) of low-carbon energy technologies can be motivated by market failures on the one hand, or by strategic industry and trade policy issues on the other. First, the reduction of greenhouse gas emissions is a global public good and unless such reduction is adequately rewarded, or emissions properly charged, the incentive to develop and deploy low-carbon technologies will be too low, see also Stern (2006). Second, research activities are accompanied by positive externalities from knowledge spillovers and without a restrictive access regime, 
innovating firms cannot fully appropriate their returns, reducing innovation efforts below socially optimal levels, see Martin and Scott (2000) and Foxon (2003). Third, capital markets suffer from information asymmetries among innovators and investors. Many investors are constrained in equity and debt capital, not only due to the limited availability of funds as a result of the financial crisis, but also since certain types of (especially small or new) actors face difficulties to raise available funds, see Hyytinen and Toivanen (2005). Last, policy intervention may relate to strategic industry and trade policy, pushing or protecting certain technologies and industries on the global market.

Different policy instruments aim at taking account of each of the above mentioned rationales. Market pull instruments, such as carbon pricing schemes or payments subsidising the deployment of certain technologies like the widely implemented national renewable support schemes, mainly address the positive externalities of clean energy production. In contrast, technology push mainly targets the correction of spillover effects accompanying the innovation process. Besides monetary transfers, technology push might also shift financial risks from entrepreneurs to public authorities by guaranteeing financial support in case research does not turn out to be successful or scalable for market implementation. Thus, technology push can also address capital market imperfections and, in case of a strong push, technology performance on the world market.

To shed light on the financial parameters that justify technology push, Figure 1 depicts a simplified illustration of the innovation chain and characterises each step in terms of its investment needs and types of risks and returns. Whereas technical risks are dominant in the very early stages of the innovation chain and innovators' main concern is the financing of the research activities, political and commercial risks become more relevant as technologies evolve along the chain.

Figure 1 Simplified innovation chain

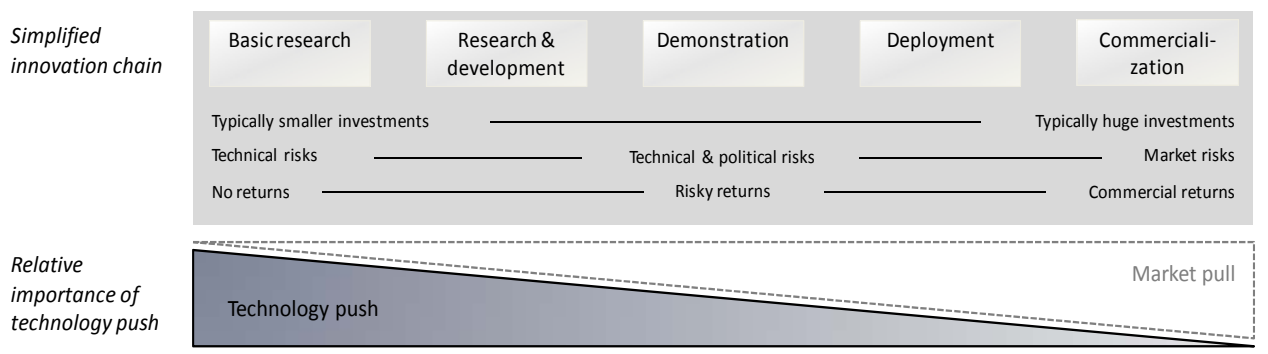

There is a consensus in energy technology policy literature that market pull alone does not lead to the desired outcomes. Instead, a well-designed policy involves pull to deal with the environmental externality, and, at the same time, complementary technology push to deal with the knowledge and spillover externalities, see Horbach (2007) or Nemet (2009). As concluded in Grubb (2004), the relative importance of technology push to market pull increases as one moves from technologies close to market competitiveness towards highly immature ones. Especially the central stages of the value chain, commercial-scale demonstration and early deployment, involve substantial investment needs accompanied by still non-negligible risks. This 'valley of death', where the key challenge is the transition from publicly co-financed to private operations, is discussed in-depth elsewhere, see Murphy and Edwards (2003) and Weyant (2011). 


\subsection{Rationales for EU involvement}

Policy intervention and corresponding policy instruments can be governed by the EU, jointly coordinated among countries, or by individual Member States who seek to intervene mainly on their home market. Nonetheless, the challenges are (at least) of European nature, with externalities and spillovers being phenomena that cross national borders. Therefore, relying only on individual Member State action is likely to lead to sub-optimal outcomes.

From an institutional perspective, there are shared competences between Member States and the EU regarding the achievement of the European environmental and energy policy goals (Art. 192 and 194, Treaty of the Functioning of the EU) as well as related to actions that ensure the conditions necessary for the competitiveness of the European industry (Art. 173). As for technology push, it is thus necessary to investigate whether there are substantial economic benefits to be gained from EU involvement, but at the same time to set those benefits into relation with the costs of pooling public regulatory power at this highest political level:

Benefits from EU intervention can be expected from the coordination of national policies. The currently implemented bottom-up approach with the 20-20-20 $\operatorname{targets}^{1}$ being specified in EU Directives (2009/28/EC; 2009/29/EC and accompanying Decision $406 / 2009 / \mathrm{EC} ; 2012 / 27 / \mathrm{EC}$ ) that have to be implemented into national laws, resulted in a wide set of national policy instruments and support programs. Technology push initiated at the EU level, in contrast, can avoid an unnecessary duplication of national or regional initiatives. A common EU funding scheme can also avoid that Member States only fund technologies being produced within their own borders and free-ride on third countries to push other technologies. Besides, different studies show that European co-funding can leverage substantial additional national and private funds, see EC (2011b) or Liljelund et al. (2011). Moreover, most of the Member States simply are too small to implement certain instruments or to compete on a global scale with economies such as the USA or China. When joint action is taken, technology but also industry and trade policies are more credible towards world market competitors, while also being more credible for attracting foreign investment. And also for overcoming the financial crisis and relaxing funding constraints, the EU has to play its role, as the financial crisis clearly is a European problem calling for European solutions.

Following the principle of subsidiarity, EU action, however, shall only be taken when it is more effective than actions at national, regional, or local level. Potential drawbacks of EU involvement might be the disregard of national specificities, the reduction of institutional competition between alternative policy approaches, and the loss of decentralised 'willingness to do more'. Considering the above arguments in favour of EU intervention, it can be conjectured that they outweigh their costs for some policy areas where strong coordination is needed (such as the EU ETS). However, at the same time when EU regulations become themselves complex and alien to national habits, also transaction costs increase and might outweigh the benefits of EU intervention. In Section 4, we will discuss the importance of recognising the subsidiarity principle and transaction costs with respect to prioritising technologies that are to be pushed on the European level. 


\subsection{Status quo of currently implemented European technology push}

As pointed out above, a mix of technology push and market pull instruments dominates relying on just one class of instrument and in the EU indeed a mix of both instruments prevails. In this respect technology push has to be evaluated in the context of implemented market pull.

The main market pull instrument is the EU-wide emission trading scheme (EU ETS) which was introduced in 2003 and substantially strengthened with the 2009 climate and energy policy package. ${ }^{2}$ The EU ETS is accompanied by a broad spectrum of national measures supporting the deployment of low-carbon technologies, see Ecofys et al. (2011). These measures aim at achieving the binding national targets for the share of renewable energy sources in gross final energy consumption by 2020 and follow an approach of indirect promotion for low-carbon technologies through guaranteeing certain revenue streams in addition to the market value of low-carbon technologies.

Complementary technology push offers the direct promotion of low-carbon technologies. At the European level, for this sake, the SET Plan has been adopted in 2008 as the so called 'technology pillar' of the EU energy and climate policy. Industrial Initiatives bring together industry, the research community, Member States and the Commission. Strategic objectives have been formulated based on a set of technology roadmaps that identify priority actions for different technology sectors, such as wind energy, solar PV and CSP, or biomass, for the decade from 2010 to 2020. More specific implementation plans, containing more detailed descriptions of proposed RDD\&D activities, as well as suggestions about potential funding sources, are developed regularly for three-year periods. However, the current SET Plan has a limited time horizon, expiring in 2020. In addition, all planning and priority setting is conducted within the individual industrial initiatives, and thus, it does not necessarily support an optimal (cost-efficient) portfolio of low-carbon technologies, i.e., decarbonisation at least cost.

Technology push in the form of direct support to innovation can involve a whole set of financing instruments including not only research grants but also low-interest loans and loan guarantees, public equity, technology prizes, et cetera. As concluded in Olmos et al. (2012), such instruments are indeed policy instruments. In addition to their function of closing the gap between the cost of innovation and funds private parties are willing to contribute, they might be able to target specific technologies and types of innovating entities. Current practice shows that subsidies in the form of grants and contracts - the most attractive form of support from the innovators' perspective, but also the most expensive one for the public sector - are, by far, the preferred policy instruments to fund clean energy innovation of any type.

Recent policy initiatives already are a first step towards a 'smarter' financing support. The European Energy Efficiency Fund is a public-private partnership offering different types of debt and equity instruments to projects dedicated to energy efficiency, small-scale renewables and clean urban transport projects. The Risk Sharing Finance Facility has been jointly developed by the Commission and the EIB to co-finance higher-risk R\&D involving complex products and technologies, or being subject to unproven markets and intangible assets. Support of up to EUR $300 \mathrm{mn}$ per project is primarily provided in the form of loans and loan guarantees and some equity financing coming from the European Investment Fund. The Horizon 2020 program will include output-based funding such as technology prizes. Loan and equity financing are expected to play a greater role, too. 


\section{Sources of uncertainty for designing optimal technology push}

Best practice for technology push will depend on the overall energy policy context. This context is uncertain, with uncertainty originating from three sources: the adequateness of the carbon price signal, the set of available decarbonisation technologies, and potential paradigm shifts in EU energy policy away from decarbonisation. As discussed below, consequences of these uncertainties might call for an even stronger technology push than today.

\subsection{Uncertain carbon prices}

The policy context for (European) technology push is defined by market pull regimes, and here foremost by the EU ETS and the adequateness of the carbon price signal. Today, it can be heavily doubted that based on the current scheme and the currently determined emission cap, carbon prices in the magnitude of those reported in different EU Energy Roadmap scenarios ${ }^{3}$ can be implemented. One can expect severe difficulties to implement a 'high-enough', adequate carbon price and also to include more types of greenhouse gas emissions into the scheme. Obviously, some sectors are more affected than others, as will be the case for different EU Member States, see Delgado (2007) and Ellerman et al. (2010). Especially countries being specialised in carbon-intensive products most likely will oppose a strong carbon pricing scheme and will advocate exemptions for individual sectors or the free allocation of emission allowances to certain user groups, a scenario that is even more relevant with the current EU and financial crises raising the question whether such a policy would be affordable for all Member States.

The recent rejection by the European Parliament of the back-loading proposal further decreases the chances that sufficiently tight emission caps will be introduced soon, and it is open whether as a result individual Member States might follow the British example. The UK Government in 2011 unilaterally introduced a carbon price floor of GBP 16/ton, following a linear path up to GBP 30/ton in 2020, see House of Commons (2013).

In summary, given the current absence of a strong enough carbon price, together with the necessity to accelerate low-carbon innovation, as highlighted in Kemfert and Schumacher (2005), Stern (2006) or Aghion et al. (2009), the need for technology push further gains in importance.

\subsection{Technological shocks}

The EU Energy Roadmap scenarios build on a menu of essentially known technologies. In 2050, the energy system will likely be extremely different than it is today. Nonetheless, the optimal portfolio of decarbonisation technologies has a very long time horizon, not only looking ahead to the 2050 target, but technological lock-ins will persist even beyond. But it is not only this very long-term nature inherent in the path dependency of technology development. Also recent events, such as the Fukushima accident, influence possible future market environments. For instance, a '2050 bridging role' was still given to nuclear in the first version of the German energy strategy in late 2010, whereas the country announced a nuclear phase out until 2022 only one year later as a response to the Fukushima accident.

Possible shocks might not only eliminate technology options, but could also add new means of decarbonisation. Whereas the International Energy Agency in its World Energy 
Outlook 2007 (when the 20-20-20 strategy was adopted by the European Council) predicted a moderate growth for US gas production and did not mention shale gas at all, the World Energy Outlook 2011 is talking about a possible 'golden age of gas'. A (more global) shale gas revolution may severely shake up our today's EU energy strategy: The production of shale gas, an unconventional gas resource, rose from less than $1 \%$ of domestic gas production in the USA in 2000 to over $20 \%$ in 2010 . Forecasts predict a continuous rise up to more than $45 \%$ by 2035, see Stevens (2012). This recent development transformed the gas market into a buyers' market and several experts see a huge potential for shale gas worldwide. ${ }^{4}$

Assuming that the USA will become a large-scale exporter of cheap gas and that it is possible to replicate the American experience in other parts of the world, the availability of cheap gas on the market would allow for a certain degree of decarbonisation at low cost (or even net benefits). Hence, the 'rational' price of carbon might well fall extremely low under the push of shale gas as a 'market-based' decarbonisation technology. Nevertheless, gas is still a fossil fuel and the 2050 decarbonisation objective cannot be reached with shifting to gas alone. Shale gas may not only substitute for dirty coal but also for expensive renewables, and the lack of a carbon price signal will inhibit investments into the development and deployment of alternative low-carbon technologies.

In summary, 2050 is a very long-term horizon and technological shocks and revolutions can have important, unpredictable impacts on the available set of and relative cost of decarbonisation technologies. There are not only substantial uncertainties regarding viable decarbonisation technologies within the context of the EU Energy Roadmap, but there are also possible futures not yet recognised in 2050 roadmaps. Hence, also technology push strategies that do not take account of technological breakthroughs or political barriers to technology deployment are likely to be ineffective.

\subsection{Paradigm shifts in EU energy policy}

Decarbonisation has become a central theme on the political agenda of European energy policy. Energy policy, however, traditionally builds upon three fundamental pillars: sustainability and competitiveness and supply security. Shifts of policy focus towards one or the other of these three paradigms have been frequently observable in the recent past. Whereas in 2007 European energy policy had a strong sustainability focus, the Russia-Ukraine gas dispute in winter 2008/2009 and resulting gas shortages also in European countries reinforced discussions about the security of energy supplies. With the financial and economic crisis, concerns about economic growth and competitiveness of domestic industries were back in the centre of political discussions.

As for shifts towards competitiveness of European firms, climate policy imposes asymmetric cost on the regulated agents and at least in the short-run bears the risks of being detrimental for economic growth. Carbon pricing increases the industry's cost, which raises concerns from an economic point of view (loss in competitiveness), but also from an environmental perspective (carbon leakage). There is considerable debate about the extent of carbon leakage and policy measures mitigating this phenomenon (e.g., Clò, 2010; Caron, 2012; Antimiani et al., 2012). But there are also considerations about positive interactions between decarbonisation and economic growth. Fankhauser et al. (2008, p.426) argue that "growth theory has long identified technical change and innovation as major source of economic growth" and that long-term dynamic innovation 
effects induced by climate policies will bring about a net job creation. However, a shift in the European policy focus towards prioritising competitiveness would certainly not improve conditions for successful implementation of decarbonisation policies and further aggravate the implementation of carbon pricing schemes with adequate price signals. Technology push in such a context clearly gains in importance.

As for shifts in favour of supply security, at first sight, there seems to be a certain conflict with the achievement of environmental objectives, in particular $\mathrm{CO}_{2}$ mitigation, since these restrictions may limit options of energy supply. A balanced portfolio ensuring a well-diversified supply mix again might call for stronger push policies. But climate policies can induce a broader use of low-carbon technologies, and thus also have a positive impact on diversification. Studying the UK electricity system, Grubb et al. (2006) find that the introduction of an emission target of $60 \%$ will lead to a substantial increase in diversity of generation sources (mainly driven by a declining dominance of gas in the fuel mix), whereas, in contrast, in the absence of any emission target, diversity decreases.

\section{Implications for European technology push}

Several implications for a feasible European technology push strategy arise. As shown, technology push is needed to account for several market failures and imperfections. Benefits from EU intervention can be expected from the coordination of national policies. In addition, existing uncertainties and possible consequences of low carbon prices, technological shocks or shifts in policy paradigm may even call for stronger technology push, if decarbonisation is to be reached by 2050. As public money for technology push is rather limited at the Member State but also at the European level, this section proposes which technology priorities offer effective no-regret push strategies. We also discuss international trade measures as a potential 'regret strategy'. Lastly, we conclude on the optimal division of Member State and EU responsibilities when pursuing these strategies.

\subsection{No-regret strategies for technology push}

Certain low-carbon technologies can become indispensable to achieve the transition to a low-carbon economy and at the same time there might be reasonable concerns that, without extra support, they will not be developed and deployed at the necessary scale and/or on time. This could, in theory, for instance be the case for carbon capture and sequestration (CCS). All scenarios of the EU Energy Roadmap contain a substantial part of electricity generation using this technology (between 10\% in the 'high RES' and 33\% in the 'Reference' case in 2050). Other roadmaps (ECF and McKinsey, 2010; Eurelectric, 2011; International Energy Agency, 2012) present very similar numbers. Hence, if the timely deployment of CCS is a necessary precondition to achieve climate objectives, further support to innovation and especially demonstration projects can be justified. ${ }^{5}$ Similar arguments also hold for other low-carbon technologies. Stronger push policies here would become even more relevant if the large-scale deployment of CCS turns out to be infeasible and/or if more Member States decide a nuclear phase-out.

Even though without detailed cost- and technology data at hand, disaggregated technology-specific recommendations as to what technologies and research activities to push are not possible, we can draw several conclusions that will generally hold: 
A prioritisation of low-carbon production technologies by policy makers entails high risks of 'picking wrong winners', especially so because future energy market developments like the evolution of shale gas production and fossil fuel prices may entirely change the benefits and market value of different production technologies.

The situation is different for certain consumption-oriented technologies, comprising mainly energy conservation and efficiency enhancing measures. Several reasons argue for pushing such technologies. First, there is a consensus that the long-term EU climate objectives cannot be reached without substantial improvements in energy efficiency, see Mundaca (2008). Moreover, due to their inherent nature of being less manufacturing-oriented but rather to a large extent relying on installing new appliances, incentivising smart behaviour, et cetera, the implementation of energy conservation measures typically is quite labour-intensive, and, therefore, entails a larger positive effect on job creation. Limited labour mobility implies that new jobs are created within the EU. Besides, pushing consumption-oriented technologies generally does not lead to large biases in energy markets, as is the case for production technologies where support for low-carbon generation will inevitably crowd out remaining competing (and also incumbent) technologies and, hence, can bias market efficiency in often unanticipated ways.

Hence, pushing consumption-oriented technologies dominates pushing production-oriented technologies in terms of both feasibility and robustness. First, the above arguments indicate that such push is politically feasible: Opposing to a push for production technologies, that often would benefit certain Member States in which the major suppliers are located, energy efficiency enhancing measures benefit all EU industries, those offering energy efficiency products and all industries applying it. Hence, this push strategy is independent of geographic location and creates jobs throughout all Member States. Second, such push is robust with respect to future energy market developments: Consuming less is a no-regret policy. The EU might well look after its own 'energy technology and security' revolution in consuming significantly less energy.

For similar reasons, pushing enabling technologies (such as grids, advanced metering or market facilitation via ICT equipment) is a valuable strategy. As for the technology group discussed above, investments typically are quite domestically labour-intensive. However, for grid infrastructures - as for enabling technologies in general - the appropriate magnitude of investment will depend on the amount and type of renewable energy that enters the power system. The optimal system architecture also will depend on whether we move towards 'European-wide energy superhighways' with massive solar energy being imported from North Africa, huge amounts of offshore wind energy being produced in the North Sea and nuclear energy from Eastern Europe contributing to Western European electricity supply, or whether we move instead towards a system of rising local energy autonomy, featured by widespread distributed generation and demand response.

\subsection{Industry and trade policy as potential 'regret strategy' for technology push}

As mentioned above, European technology push can have its justification as a means to respond to fierce global competition in green-tech markets and to help to keep wealth within the Union. Whereas the burden to finance market pull measures always is with consumers and tax payers but benefits can be reaped by both domestic innovators and producers, but also market entrants from outside the EU, technology push can be 
designed such that it explicitly favours domestic players. Targeting specific technologies also allows policy makers to accelerate technology development and to support industrial leadership. This strategy is promising especially for high-tech segments or parts of the value chain that cannot be outsourced to low-cost competitors.

Industry policy can either rely on competitive forces to enable (green) growth, or might compromise on competition within the EU in favour of EU champions that compete globally. The long lasting debate just became topical once more with the recent EU Communication on industrial policy (EC, 2012). Trade policy measures may either explicitly support home technologies on global markets (via subsidies), or protect them from foreign competition (via import quotas or tariffs). If the EU was the first mover, the rationale is to shift profits from foreign to domestic firms. Early literature on strategic trade policy (Spencer and Brander, 1983; Krugman, 1987) finds that, if an industry is characterised by increasing returns to scale, subsidising home firms that then can commit to an increased future output, threatens the foreign firm, which will decrease its output to not lower market prices. Subsidies given to the home firm are outweighed by the profits shifted from the foreign to the home firm. Whenever the EU would have to react to such measures undertaken by other countries, the rationale is to sanction the first mover.

The global market for clean technologies is huge in volume. According to Berger and WWF (2012), in 2011, the market volume grew by 10\% to about EUR 198 bn. Furthermore, markets are relatively new and often not perfectly competitive. Hence, it is tempting for governments to engage in trade policy to push domestic firms. Current trade disputes related to clean technologies, however, illustrate the complexity of trade policy. Most prominently, China is heavily supporting its solar PV industry, leading to anti-dumping counter measures by the USA and the EU. Likewise, but on a smaller scale, Argentina is currently filing a case at the WTO, arguing that Spain was banning imports of biodiesel from Argentina by obliging consumers to buy biodiesel produced in Spain to fulfil EU targets on renewable energy.

Such policy measures also bear considerable risk. Besides provoking counter measures, subsidising home technologies on the world market might lead to falling prices and vanishing industry profits. Within the above example, China's aggressive industry policy led to a drastic fall of the world price of solar panels and hence the effectiveness of this policy in shifting profits can be doubted. China's manufacturing capacity grew so much that an enormous oversupply was created.

In summary, thus, it has to be noted that strategic industry- and trade policy measures might be possible regret measures. There is a fine line between supporting technologies and subsidising industries. The strong reliance on competitive forces as outlined in several EU Directives should be maintained.

\subsection{Division of Member State and EU responsibilities}

While especially for industry and trade policy strategies for green technologies a joint European approach is beneficial, the overall policy design for technology push, however, should rely to a large extent on bottom-up participation. Especially technology projects with 'normal risk and return profiles' are well suited to be supported by individual Member States, leaving high-risk support for the EU. While a bottom-up approach is certainly needed for national action plans and national funding, also the push coming from the European level will be bargained beforehand. Political considerations, such as 
who are beneficiaries of support, will aggravate the planning and priority setting for technologies.

These barriers become even larger since Member States are inhomogenous in their technology base and ability to finance. The economic and financial crisis has affected all Member States, but not all in the same way and to the same extent. Less affected countries, mostly in northern Europe, have entirely different starting position for decarbonisation policies than more affected Member States, mostly in southern Europe. On the one hand, there are a few countries, such as Germany or the Netherlands, which can benefit from relatively low financing cost, public funding opportunities and a quite high consumer willingness to pay for energy policy. On the other hand, there are many countries that suffer from extremely high financing cost, highly limited public funds, and consumers not willing, or able, to afford low-carbon technology support. In addition, low-carbon technology bases range from strong low-carbon industry positions, for e.g., wind energy in Germany or Denmark, or nuclear in France, to countries that do not have any of those or similar technology advantages yet. These differences hamper agreements on a unified approach for technology support. Therefore, designing an energy technology policy top-down is difficult to sustain, which points out the need for decentralised solutions co-existing to European funding and support schemes. Decentralised solutions further include possibilities to adapt burden sharing to national conditions and needs.

\section{Conclusions}

Currently implemented EU policies supporting innovation in low-carbon technologies are expiring in 2020 and today's period of austerity has imposed tight constraints on national budgets and has forced governments to rethink fiscal policies, including support for research and innovation. This leaves the EU with the mandate to establish a clear-cut, post-2020 energy technology policy. The main long-run objective of such an energy technology policy is to foster the achievement of the ambitious decarbonisation goal for 2050. Policy makers, however, face several sources of uncertainty, including uncertainty about future carbon prices, uncertainty about technological change and uncertain or alternating policy paradigms that might shift the focus from decarbonisation towards competitiveness or energy supply security.

This article argues that public support for innovation in energy technologies is needed to correct for market failures and imperfections, as well as to fully exploit trade opportunities of such technologies on global markets. Benefits from EU intervention can be expected from the coordination of national policies. Regarding the choice of technologies to be pushed, certain low-carbon technologies can become indispensable to achieve the transition to a low-carbon economy and at the same time there might be reasonable concerns that without extra support they will not be developed and deployed at the necessary scale and/or on time. Moreover, for support to be robust against all uncertain market, technological and political developments, technology push should put strong emphasis on consumption-oriented and enabling technologies, as these offer no-regret strategies in any future context.

Also strategic industry and trade measure could be used to push technologies on the world market, but have to be implemented with care, foreseeing potential reactions from other players and being coherent with trade regulations. There is a fine line between 
supporting technologies and subsidising industries. The strong reliance on competitive forces as outlined in several EU Directives should be maintained.

\section{Acknowledgements}

A research grant from the FP7 Programme (Research Project THINK) is gratefully acknowledged. While as a part of the THINK project DG ENER provided helpful feedback, the expressed views are solely those of the authors. The authors would like to thank two anonymous referees for helpful comments and suggestions. The usual disclaimer applies.

\section{References}

Aghion, P., Hemous, D. and Veugelers, R. (2009) No Green Growth Without Innovation, Bruegel Policy Brief 2009/07.

Antimiani, A., Costantini, V., Martini, C., Salvatici, L. and Tommasino, M.C. (2012) 'Assessing alternative solutions to carbon leakage', Energy Economics, Vol. 36, No. 2, pp.299-311.

Berger, R. and WWF (2012) Clean Economy, Living Planet: The Race to the Top of Global Clean Energy Technology Manufacturing, Report commissioned by WWF.

Caron, J. (2012) 'Estimating carbon leakage and the efficiency of border adjustments in general equilibrium - does sectoral aggregation matter?', Energy Economics, Vol. 34, No. 6, pp.S111-S126.

Clò, S. (2010) 'Grandfathering, auctioning and carbon leakage: assessing the inconsistencies of the new ETS Directive', Energy Policy, Vol. 38, No. 5, pp.2420-2430.

Delgado, J. (2007) Why Europe is Not Carbon Competitive, Bruegel Policy Brief 2007/05.

EC (2011a) A Roadmap for Moving to a Competitive Low-carbon Economy in 2050, COM(2011) 112.

EC (2011b) Review of European and National Financing of Renewable Energy in Accordance with Article 23(7) of Directive 2009/28/EC, SEC(2011) 131.

EC (2012) A Stronger European Industry for Growth and Economic Recovery, COM(2012) 582.

ECF and McKinsey (2010) A Practical Guide to a Prosperous Low Carbon Europe, European Climate Foundation, London.

Ecofys, Fraunhofer ISI, EEG and LEI (2011) Renewable Energy Policy Country Profiles, 2011 version, Report prepared within the Intelligent Energy Europe project RE-Shaping - Shaping an effective and efficient European renewable energy market.

Ellerman, A.D., Convery, F.J. and de Perthuis, C. (2010) Pricing Carbon: The European Union Emission Trading Scheme, Cambridge University Press, Cambridge.

Eurelectric (2011) Power Choices - Pathways to Carbon-neutral Electricity in Europe by 2050, Brussels.

Fankhauser, S., Sehlleier, F. and Stern, N. (2008) 'Climate change, innovation and jobs', Climate Policy, Vol. 8, No. 4, pp.421-429.

Foxon, T.J. (2003) Inducing Innovation for a Low-carbon Future: Drivers, Barriers and Policies, Report for The Carbon Trust.

Grubb, M. (2004) 'Technology innovation and climate change policy: an overview of issues and options', Keio Economic Studies, Vol. 41, No. 2, pp.103-132.

Grubb, M., Butler, L. and Twomey, P. (2006) 'Diversity and security in UK electricity generation: the influence of low-carbon objectives', Energy Policy, Vol. 34, No. 18, pp.4050-4062. 
Hirschhausen, C.v., Haftendorn, C., Herold, J., Holz, F., Neumann, A. and Ruester, S. (2010) Europe's Coal Supply Security: Obstacles to Carbon Capture, Transport and Storage, CEPS Policy Brief 223/2010.

Horbach, J. (2007) 'Determinants of environmental innovation: New evidence from German panel data sources', Research Policy, Vol. 37, No. 1, pp.163-173.

House of Commons (2013) Carbon Price Floor, House of Commons Library, SN/SC/5927.

Hyytinen, A. and Toivanen, O. (2005) 'Do financial constraints hold back innovation and growth? Evidence on the role of public policy', Research Policy, Vol. 34, No. 9, pp.1385-1403.

International Energy Agency (2012) Energy Technology Perspectives 2012 - Pathways to a Clean Energy System, Paris.

Kemfert, C. and Schumacher, K. (2005) Costs of Inaction and Costs of Action in Climate Protection - Assessment of Costs of Inaction or Delayed Action of Climate Protection and Climate Change, German Institute of Economic Research, Final Report Project FKZ 90441362 for the Federal Ministry for the Environment.

Krugman, P.R. (1987) 'Is free trade passé?', Economic Perspectives, Vol. 1, No. 2, pp.131-144.

Liljelund, L.E., NúnñezFerrer, J., Egenhofer, C. and Alessi, M. (2011) The SET Plan - From Concept to Successful Implementation, CEPS Task Force Report.

Martin, S. and Scott, T.J. (2000) 'The nature of innovation market failure and the design of public support for private innovation', Research Policy, Vol. 29, Nos. 4-5, pp.437-447.

Mundaca, L. (2008) 'Markets for energy efficiency: exploring the implications of an EU-wide 'Tradable White Certificate' scheme', Energy Economics, Vol. 30, No. 6, pp.3016-3043.

Murphy, L.M. and Edwards, P.L. (2003) Bridging the Valley of Death: Transitioning from Public to Private Sector Financing, Working Paper NREL/MP-720-34036, National Renewable Energy Laboratory.

Nemet, G.F. (2009) 'Demand-pull, technology-push, and government-led incentives for non-incremental technical change', Research Policy, Vol. 38, No. 5, pp.700-709.

Olmos, L., Ruester, S. and Liong, S.J. (2012) 'On the selection of financing instruments to push the development of new technologies: application to clean energy technologies', Energy Policy, Vol. 43, No. 4, pp.252-266.

Ruester, S., Schwenen, S., Finger, M. and Glachant, J-M. (2013) A Post-2020 EU Energy Technology Policy: Revisiting the Strategic Energy Technology Plan, EUI Working Paper No. EUI RSCAS 2013/39.

Spencer, B. and Brander, J. (1983) International R\&D Rivalry and Industrial Strategy, NBER Working Paper No. 1192.

Stern, N. (2006) Stern Review on the Economics of Climate Change, Cambridge University Press.

Stevens, P. (2012) The 'Shale Gas Revolution': Developments and Changes, Chatham House Briefing Paper.

Weyant, J.P. (2011) 'Accelerating the development and diffusion of new energy technologies: beyond the 'valley of death", Energy Economics, Vol. 33, No. 4, pp.674-682.

\section{Notes}

1 I.e., a 20\% reduction in EU greenhouse gas emissions from 1990 levels; a 20\% share of EU energy consumption produced from renewable resources; and a $20 \%$ improvement in energy efficiency - all by 2020 .

2 Directive 2009/29/EC considers a single EU-wide cap on emission allowances from 2013 on, the stepwise replacement of a free allocation by auctioning, and an enlarged list of activities and greenhouse gases covered. Decision 2010/634/EU sets the total EU-wide amount of allowances at $2,039 \mathrm{mn}$ for 2013 . The cap will decrease by $1.74 \%$ per year, with this factor to be reviewed by 2020 . 
3 Carbon prices in the underlying simulation exercises are determined such that 2050 targets are reached, assuming equal prices/values for ETS and non-ETS sectors. These prices range between 234 and $310 \mathrm{EUR} / \mathrm{t}$, see EC (2011a).

4 Indeed, there appear to be large quantities of technically recoverable resources. China, for instance, is pushing strongly the development of its potential. However, uncertainty about both volumes and costs persists. US companies currently produce from very large and shallow plays, whereas resources in other areas tend to be smaller and located in greater depths, increasing exploration and production costs. There is also a tendency to correct estimates on available volumes downward: in early 2012 , Poland reduced its potential by $85 \%$ - from $5,300 \mathrm{bcm}$ to below $800 \mathrm{bcm}$. Furthermore, shale gas is produced based on horizontal drilling and hydraulic fracturing which involves the injection of chemicals. Severe environmental concerns have created strong local oppositions, and France or Bulgaria have already banned shale gas operations.

5 However, as discussed elsewhere in-depth (see e.g., Hirschhausen et al., 2010), CCS can only thrive, if at the same time financial, political and regulatory risks are reduced. Moreover, public opposition, which can make the implementation of CCS projects unfeasible, is not to be underestimated. 